\title{
Beckwith Wiedemann Syndrome with Congenital Heart Disease - A Case Report
}

\author{
Syed Athhar Saqqaf1, Divya Ramamoorthy², Aditi Jhamb³ ${ }^{3}$ Sachin Yedve ${ }^{4}$, Amar Taksande $^{5}$ \\ 1, 2, 3, 4, 5 Department of Paediatrics, Jawaharlal Nehru Medical College, Sawangi, Wardha, Maharashtra, India.
}

\section{INTRODUCTION}

Beckwith - Wiedemann Syndrome (BWS) usually present at birth is an overgrowth disorder, characterized by variable spectrum of clinical findings. The classical features include macrosomia, macroglossia, midline abdominal wall defects, hypoglycaemia in neonates and ear creases. We present a six-month-old female child with history of difficulty in sucking.

Macrosomia with macroglossia was present on general examination. The infant had continuous murmur which was best heard at infraclavicular area. Mild hepatomegaly with splenomegaly was present on per abdominal examination. Echocardiography study revealed moderate size patent ductus arteriosus (PDA) with left to right shunt without pulmonary hypertension which was closed by PDA device. Beckwith - Wiedemann syndrome is an overgrowth disorder in paediatrics age group. It is estimated that BWS has an incidence of 1 in 13,700 population with equal chances in both male and female. ${ }^{1}$ An American pathologist, Dr. John Bruce and a German paediatrician named Dr. Hans-Rudolf Wiedemann, had suggested about this condition separately. Initially it had been termed EMG (exomphalos, macroglossia, and gigantism) syndrome which was thereafter referred to as Beckwith Wiedemann syndrome. Genetically BWS is said with an alteration of the organic phenomenon at the petit arm of chromosome 11 (11p15) causing over activity of growth factor IGF 2 gene and/or no active copy of the inhibitor gene of cell proliferation - CDKN1C. Child presents with the mixture of congenital abdominal wall defects as exomphalos, macroglossia and gigantism. Some additionally present also with hemihypertrophy port-wine stain, midface hypoplasia, prominent occiput, genitourinary anomalies like enlarged kidneys, musculoskeletal abnormalities, cardiac defects and deafness..$^{2,3}$

These children may grow at an accelerated pace during the latter half of the antenatal period continuing in the initial few years of life. Though, their adult heights are usually in the normal range. Here, we report a six-month-old female infant, who presented with evident features of BWS with congenital heart disease.

\section{PRESENTATION OF CASE}

A 6-month-old female child was admitted for difficulty in sucking. She was delivered via normal vaginal delivery with birth weight of $5 \mathrm{~kg}$ and had history of non-intensive care unit (NICU) stay in view of large for gestational age with macrosomia and macroglossia. There was no family history of heart diseases, congenital anomaly or limb anomaly. She was discharged in stable condition without complication. On admission, her weight was $9 \mathrm{~kg}$, height of $60 \mathrm{~cm}$ and head circumference was $39 \mathrm{~cm}$. Her vitals were: Heart rate: $126 / \mathrm{min}$, respiratory rate: $38 / \mathrm{min}$, peripheral pulses: well felt and oxygen saturation: $98 \%$ in all four limbs. On general examination, patient had afebrile, pallor, no cyanosis and clubbing.
Corresponding Author: Dr. Syed Athhar Saqqaf, Department of Paediatrics, Jawaharlal Nehru Medical College, Sawangi, Wardha, Maharashtra, India.

E-mail: athhar94@gmail.com

DOI: $10.14260 / j e m d s / 2021 / 547$

How to Cite This Article:

Saqqaf SA, Ramamoorthy D, Jhamb A, et al. Beckwith Wiedemann syndrome with congenital heart disease - A case report. J Evolution Med Dent Sci 2021;10(32):26842686, DOI: 10.14260/jemds/2021/547

Submission 24-04-2021,

Peer Review 06-07-2021,

Acceptance 11-07-2021,

Published 09-08-2021.

Copyright (C) 2021 Syed Athhar Saqqaf et al. This is an open access article distributed under Creative Commons Attribution License [Attribution 4.0 International (CC BY 4.0)] 


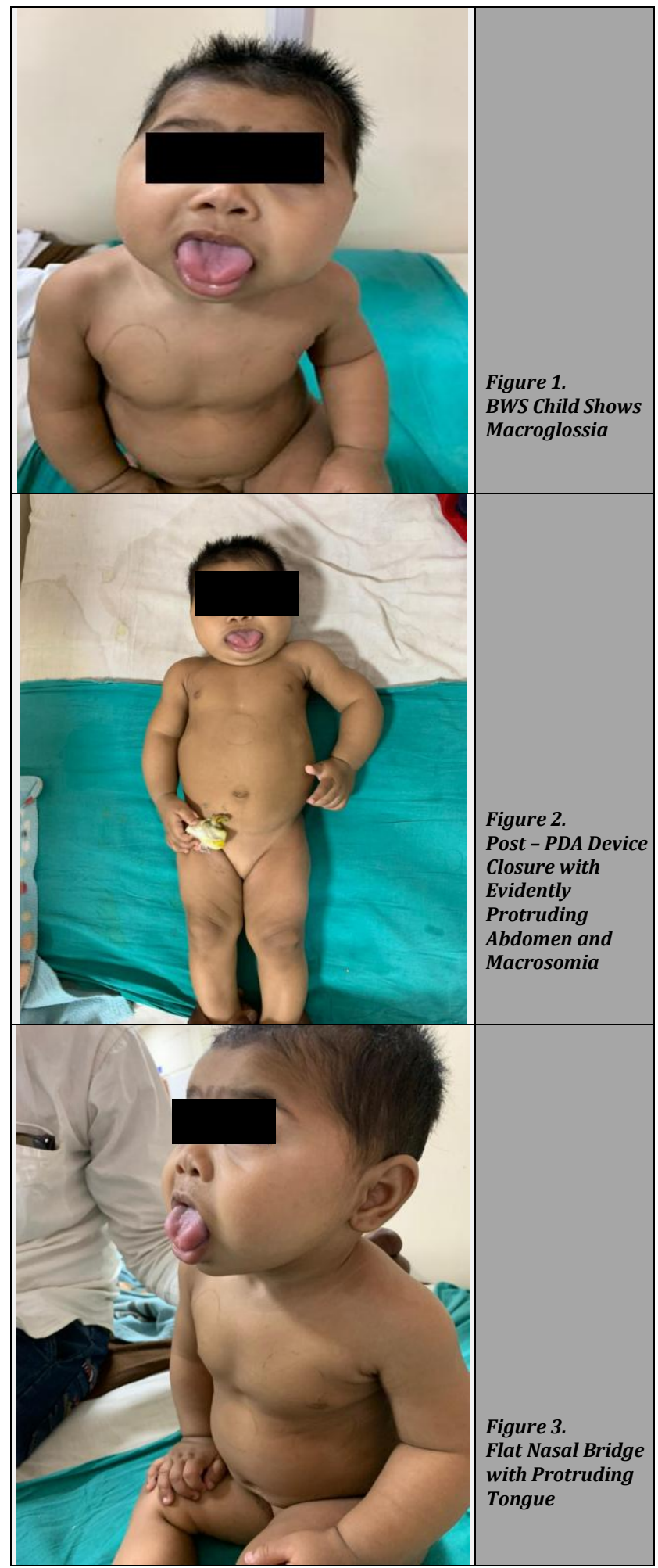

Macrosomia with macro glossitis was present. Anterior fontanelle was open and at level. There were no signs of respiratory distress. On cardiovascular examination, the continuous murmur was present, best heard at the infraclavicular area. Bilateral air entry was equal on respiratory examination. Mild hepatomegaly with splenomegaly was present on per abdominal examination. Others systemic examination was normal. Her ophthalmic evaluation was within normal limits.

The haematological work up was normal. Thyroid profile was within normal limits. Chest $\mathrm{x}$-ray showed mild cardiomegaly with normal lung field. Ultrasound abdomen and pelvis was suggestive of enlarged liver and spleen. Magnetic resonance imaging (MRI) brain was normal. Echocardiography study demonstrated moderate size patent ductus arteriosus with left to right shunt without pulmonary arterial hypertension (PAH). PDA was closed by device closure.

\section{DISCUSSION}

BWS is diagnosed clinically, but genetic testing is better advised in suspected familial cases. Clinically, BWS manifest in different forms, it's most commonest features being macroglossia (97 - $100 \%$ ) which can be asymmetric, abdominal wall defects (77 - $80 \%$ ) most commonly omphalocele, hypoglycaemia in neonatal period $(63 \%)$ and macrosomy (68\%). ${ }^{4}$ Affected child may have asymmetric body growth of one side or hemi hyperplasia, other presentations include microcephaly, ear creases or posterior helix pits, midline abdominal wall defects like diastasis recti and umbilical hernia, birth defect like renal alterations, cleft palate, visceromegaly, refractory hyperinsulinemia, polydactyly. Neurologic complications are rare. These children have a higher risk to develop tumours during childhood, peculiarly Wilm's tumour, hepatoblastoma, rhabdomyosarcoma. . $^{1,2}$ These children have increased chances of organomegaly involving either single or multiple organs like spleen, liver, kidney, supra-renal glands, and pancreas. Pathognomonic finding of BWS is fetal adrenocortical anomalies. Bilateral or unilateral renal anomalies may include Wilm's tumour, renal medullary dysplasia, nephrolithiasis and nephrocalcinosis. About $20 \%$ of children with BWS are found with cardiac malformations and half of them present with cardiomegaly, which then resolves spontaneously. Rarely, it may also present with cardiomyopathy. In our case, the child had patent ductus arteriosus which was successfully closed by PDA device.

Recognizing BWS is challenging due to the variable manifestations present in children. The unavailability of an easy diagnostic test further adds to the case. To simplify and standardize the diagnosis of BWS, DeBaun et al. have designated a child as to have BWS, if he/she has at least any two of the five features that are commonly known to be associated with the condition, i.e. macrosomia, macroglossia, midline abdominal wall defects, neonatal hypoglycaemia and ear creases. ${ }^{2}$ Complications associated with conditions like hypoglycaemia can occur, but if intervened at the appropriate time can prevent any sequelae. Imprinting is associated with structural modifications of deoxy ribo nucleic acid (DNA), like methylation or lack of acetylation. Several $11 \mathrm{p}$ genes are imprinted like IGF - 2 (the gene for insulin like growth factor 2 [IGF - 2]), p57 (a cation - independent cyclase), H19 and gene for insulin. ${ }^{5}$ BWS phenotype can present with various variations, like for instance the diagnosis could also be considered when a child presents only with hemi-hyperplasia and port-wine stain or possible ear creases. Macroglossia is the protrusion of tongue; In BWS, it becomes less prominent as the child grows and often doesn't require treatment. Though, in severe cases, it can lead to respiratory distress, speech and feeding difficulties which may later demand a partial glossectomy involving the cranio-fascial surgery team. It is recommended that this surgery be performed between the age of 3 months to 6 months, by some surgeons, though the 
best time for such surgeries isn't defined. Partial glossectomy involves the removal of a small part of the tongue, such that it fits well within the mouth and thereby allows proper and adequate jaw and tooth development. ${ }^{3}$ The extreme condition - death, may occur as a result of associated complications like prematurity, hypoglycaemia, cardiomyopathy or maybe even tumors. ${ }^{1}$ All children suspected with BWS should be scanned for cancer. Abdominal sonography should be conducted once in every 3 months at least until eight years of age and blood alpha-fetoprotein (AFP) estimation should be done every 6 weeks till the child is of four years of age. ${ }^{2}$ Current evidence shows that prognosis depends on the associated congenital malformation including the severity of the cardiac involvement may have worse prognosis.

\section{CONCLUSIONS}

In conclusion, we report a rare case of BWS with moderate size PDA without PAH. The careful examination should be completed in all patients presented with dysmorphic features to diagnose as BWS and also evaluated for congenital heart defect.
Financial or other competing interests: None.

Disclosure forms provided by the authors are available with the full text of this article at jemds.com.

\section{REFERENCES}

[1] Ashok K, Mayank V, Abhishek M, et al. Beckwithwiedemann syndrome-a rare case report. Int J Health Sci Res 2014;4(11):266-9.

[2] Mansoor KP, Ravikiran SR. A case report of beckwith wiedemann syndrome with prolonged hypoglycaemia and requiring hemi-glossectomy. J Med Sci Clin Res 2018;6(8).

[3] Hassan K, Paul A, Shibli M. Beckwith wiedemann syndrome: a case report. Faridpur Med Coll J 2016;10(2):87-8.

[4] Reik W, Maher ER. Imprinting in clusters: lessons from beckwith-wiedemann syndrome. Trends Genet 1997;13(8):330-4.

[5] Pettenati MJ, Haines JL, Higgins RR, et al. Wiedemannbeckwith syndrome: presentation of clinical and cytogenetic data on 22 new cases and review of the literature. Hum Genet 1986;74(2):143-54. 